\title{
Seguridad Social
}

\author{
Por el Dr. MARCELO LLOSA G.
}

\begin{abstract}
"Desean lograr la mayor colaboración entre todas las Naciones en el campo económico con el objeto de asegurar para todos, mejoras en las condiciones de trabajo, reajustes económicos y seguridad social".-(Quinto punto de la Carta del Atlántico).
\end{abstract}

La irregularidad de ingresos constituye causa más frecuente de alteración que el ingreso reducido. 'Los hombres se acomodan a cualquier ingreso que no se encuentre por debajo del Mínimum Vital, pero pocos hombres proveen adecuadamente para contingencias. Donde el margen entre lo recibido y los gastos necesarios es mínimo, cualquier interrupción del ingreso constituye sufrimiento y penuria. Aun en los casos en que los ingresos sean suficientes para hacer una previsión por medio del ahorro o del seguro, ella no se hace en la mayoría de los casos. Cómo mitigar el sufrimiento consiguiente entre las grandes masas de población deviene en uno de los más urgentes problemas sociales. Se le presta gran atención' hoy en día y ello no se debe completamente a una mayor irregularidad en los ingresos o a una mayor necesidad de previsión para contingencias, sino a que el mundo actual es claramente más sensible a los males sociales. En nuestro país, como en todas partes, condiciones aceptadias en años anteriores como cosa corriente son consideradas ahora como intolerables y se hace un esfuerzo tenaz para remediarlas.

Los accidentes, las enfermedades, la vejez y la desocupación, son las causas principales de irregularidad en los ingresos que hoy se tratan de evitar pero sin perder de vista una pregunta principal de principio: ¿ Hasta dónde puede concederse ayuda sin minar el carácter y la previsión del individuo?

Ninguna fase del esfuerzo social ilustra más claramente el conflicto entre la simpatía y el juzgamiento sereno que las medidas tomadas a favor de los indigentes. Siempre habrá una previsión para socorrer al indigente. E1 impulso altruista nunca permite que se lleguen a últimos grados de miseria si ello es dable evitarlo y todos los sistemas de Seguros Sociales dejarán al margen casos de mala suerte, improvidencia y ruina. Siempre habrá ocasión para la caridad y ésta corre en todos los casos el riesgo de desmoralizar al recibidor de la misma.

Por su mayor gravedad, interesa la ayuda que se presta a adultos en completa posesión de sus facultades, es decir, los no inválidos, ancianos o muti- 
lados. La caridad en relación a estos adultos es el más peligroso de los sistemas de ayuda que puede prestar una sociedad. La certeza del mantenimiento es el mayor enemigo para el vigor y la independencia del hombre. La historia de la "Ley de Pobres" en Inglaterra, nos muestra cómo un estrato íntegro de la población, en este caso los trabajadores agrícolas, puede ser desmoralizada por la ayuda caritativa sin distinción.

Los investigadores de la ley antedicha, durante lós años 1823 a 1834 después de apreciar la experiencia de Inglaterra anterior a la gran reforma de esa época llegaron a la conclusión de que la única manera segura de administrar la denominada "ayuda de pobres" a los adultos sanos era el concentrarlos en "casas de trabajo" o de "mendicantes". El socorro exterior sería abolido en base al principio poderoso que se enunciaba así que el socorro sea efectivo pero no atractivo. Por generaciones la abolición de la ayuda exterior fué contemplada por los ingleses como el único medio posible de cumplir con el principio antedicho. Se creyó que era el sine qua non de la exitosa administración de la ley de pobres. Este auxilio no desapareció en Inglaterra ni aun para los sanos. Mayor experiencia y reflexión han hecho menos segura la convicción de que debía ser eliminado. La casa de trabajo en sí, es muchas veces escuela de desmoralización y el auxilio por medio de ella, que se precisa sea inatractivo, deja de serlo con el hábito. La clave para la administración de la moderna caridad es la diferenciación en el tratamiento de las varias clases de personas necesitadas. Se admite que el auxilio exterior es un medio muy peligroso, mejor suprimirlo del todo que usarlo libremente pero, con precaución y especialmente como medio de resolver una crisis pasajera sirve mejor que la "casa de mendicantes". Así mismo el auxilio que podríamos denominar interno: cuidados institucionales, debe ser de varias clases: para los viejos y los jóvenes; los enfermos y los sanos; el vago habitual y el trabajador en necesidad momentánea. El complejo problema de la administración de la caridad, tema de una vasta literatura, es similar al de los Seguros Sociales.

El principio es hoy: Ayudar al pobre de tal manera que se le fortalezca permanentemente.

Es indudable que el sistema más digno es el de los Seguros Sociales que tiende a extenderse por todas las naciones.

Los Seguros Sociales pueden ser divididos en cuatro grandes campos que son los que a su vez causan mayores irregularidades en los ingresos: Accidentes, Enfermedades, Vejez y Desocupación.

La previsión de los accidentes se logra ya sea mediante la organización directa de los patronos en Asociaciones de Seguros o imponiéndose una obligación contra la cual pueden asegurarse en compañias de seguros ya constituídas. El primer sistema es el británico, el segundo el alemán.

Nuestra Ley de Accidentes de Trabajo N ${ }^{\circ} 1378$ de 20 de Enero de 1911 y sus ampliatorias, hace responsable al Empresario por los accidentes que ocurran a sus obreros y empleados en el hecho del trabajo o con ocasión directa de él. Permite al Empresario sustituir esta obligación por el seguro individual o colectivo de sus obreros y empleados. En caso de no tener seguro debe consignar una suma determinada para cubrir su obligación en un "fondo de garantía". Prima el sistema alemán ya que todos los seguros son tomados en compañías aseguradoras.

E1 Seguro contra Enfermedad es uno de los más factibles ya que una larga observación ha permitido el logro de datos adecuados sobre la frecuencia de las enfermedades en las grandes comunidades modernas, y de la mayor frecuencia en relación con la mayor edad; mientras que las ganancias 
progresivas en mejores métodos de vida sana han introducido un factor de seguridad que no se encuentra en el seguro de accidentes.

Este Seguro conjuntamente con el de Maternidad, Vejez y Muerte como también de Invalidez, corre a cargo de la Caja Nacional de Seguro Social Obligatorio, organismo que se encuentra regido por las leyes Nos. 8433 de 12 de Agosto de 1936; 8509 de 23 de Febrero de 1937 y por el Reglamento de estas leyes expedido el 18 de Febrero del año 1941.

Al cubrir el riesgo de enfermedad se plantea un serio problema con la Tuberculosis y el Paludismo que constituyen enfermedades endémicas en el Perú. Las personas que sufran en forma crónica estas enfermedades no deben estar comprendidas dentro de un Régimen de Seguros Sociales sino ser atendidas por un Plan Nacional con fondos del Estado. Las bases para este Plan Nacional puede pensarse que han sido dadas por el Gobierno anterior con la iniciación de la Campaña contra la Tuberculosis cuyos primeros resultados hasta ahora no son conocidos.

La Clase Media que es la que más sufre las desigualdades sociales, ya sea por no tener conciencia de clase, ya por formar el límite entre las otras clases, debe también ser comprendida de inmediato en el régimen de Seguros Sociales, bien dentro de là organización actual, bien dentro de una organización propia. Lo segundo es más apropiado por cuanto técnicamente no es recomendable una organización general de empleados y obreros.

Las Pensiones de Vejez constituyen un problema más complejo. Si las mismas se hacen sobre bases no contributorias, vienen después de la previsión de accidentes en facilidad y simplicidad. Pero si son puestas sobre base contributiva - que en principio es preferible - ellas envuelven el cobro de primas sobre un período de muchos años. la inversión de fuertes sumas. archivos eficientes, previsión para casos de cambio de domicilio y de ocupación. Al igual que en el Seguro de Enfermedad los problemas administrativos son altamente complejos. Un sistema obligatorio y universal, con su necesidad de registros, de chequeos elaborados, de asistencia y supervigilancia médica y las contribuciones de los patronos, sólo puede ser logrado por una legislación adecuada y hacerse efectivo bajo una administración a la vez estricta y humana.

Las Pensiones de Vejez corren a cargo de la Caja Nacional de Seguro Social Obligatorio y se forman a base de una contribución tripartita: patrono, asegurado y Estado. Este riesgo de vejez todavía no ha sido cubierto por la Caja en ningún caso, desconociéndose por tanto los defectos que pueda tener en su aplicación.

La Desocupación presenta problemas aún más serios que los Accidentes, Enfermedades y Vejez.

Los Socialistas como Mark y Rodbertus sostienen que se produce una larga reserva de trabajadores desocupados necesariamente dentro del sistema capitalista. Los defensores del sistema capitalista sostienen que una provisión permanente de trabajadores desocupados tiende a encontrar su propia solución; trae una competencia por ocupaciones, una puja de obrero contra obrero, un reajuste de condiciones entre patronos y obreros y el logro final de un estado de equilibrio en que todos ellos son absorbidos en la industria.

La dificultad fundamental estriba en lo siguiente: ¿Cómo evitar que el beneficio de desocupación desmoralice al recibidor del mismo? Si todos los hombres fueran ansiosos en la búsqueda de trabajo, la ayuda en caso de desocupación. ya sea por el seguro o por otro medio, sería un asunto comparativamente sencillo. Pero para la mayoría de los hombres, el tener el susten- 
to asegurado hasta que se encuentre un empleo hace probable que ese empleo no se busque.

Como medidas para combatir la desocupación se estila en la mayoría de los países la constitución de "bolsas de trabajo" y los trabajos en Obras Públicas. En el Perú a raíz de la crisis del año 1930 se implantaron las Juntas Pro-Desocupados (que continúan en funciones hasta la fecha sin necesidad alguna), para combatir la desocupación. En la actualidad podemos sostener que nuestro país con una industria incipiente y con escasez de brazos no sufre Desocupación la que constituye un fenómeno inherente a los países altamente industrializados.

Interesante es ver cómo afrontan la Seguridad Social distintos pueblos de la tierra:

\section{Nueva Zelandia}

Este país es denominado "El Laboratorio del Socialismo". Experimentos sociales y métodos Económico-Socialistas han dado resultado en Nueva Zelandia pero bajo condiciones que no son fáciles de duplicar en otras partes del mundo. Entre éstas podemos señalar: Ser miembro de la Comunidad Británica de Naciones y como tal contar con la protección del lmperio en el terreno militar y en el económico; la ventaja de ser pequeña tanto en tamaño como en población; primordialmente agrícola ha prosperado con sus exportaciones de mantequilla, queso, lanas, carnes ovinas y vacunas, $75 \%$ de las cuales iban a las Islas Británicas, las que a su vez le han proporcionado artículos manufacturados de toda clase.

En este medio es que los Neo-Zelandeses han desarrollado un sistema bajo el cual cualquier persona que quiera trabajar tiene asegurado por lo menos un ingreso adecuado y permite a aquellos que por la edad o por invalidez no pueden trabajar, sentirse seguros de que un arreglo colectivo les dispensará todo lo que les es necesario para su bienestar.

El cuidado del Estado para sus ciudadanos comienza antes de que éstos vengan al mundo y continúa hasta que éstos abandonan el mundo. No sólog es gratuita la atención para la mujer grávida sino que se le proporciona con igual carácter de gratuitidad una enfermera dos semanas antes del parto que continúa hasta que no sean necesarios sus servicios.

Una viuda con cuatro hijos menores todos de 16 años puede por ejemplo, siempre que sus ingresos sean menores de $\$ 16.60$ centavos a la semana, calificarse para recibir del Estado un ingreso adicional de $\$ 10.79$ a la semana. Esta cantidad tiene el mismo poder adquisitivo que $\$ 20$ en los Estados Unidos de Norte América.

Los niños tienen derecho a servicio dental gratuito desde que tienen 5 años y hasta la edad de 12 años y actualmente existe un proyecto para extender este servicio dental gratuito de por vida, tal como lo son ahora los servicios médicos y hospitalarios, incluyendo las medicinas.

E1 servicio médico gratuito es una innovación introducida a principios de la actual guerra. Fija un honorario de $\$ 1.25$ por llamadas durante el día $y$ casi el doble por llamadas durante la noche y consultas en Domingos y Feriados. Los médicos, si así lo desean, pueden tratar de cobrar más que el honorario fijado y si el paciente lo puede pagar lo hace, obteniendo un recibo del médico que lo hace efectivo contra el Estado. Si no puede pagar honorario alguno firma una declaración al efecto y el Estado paga al médico.

Desde el año 1940 la hospitalización y tratamiento han sido gratuitos para los ciudadanos. Noventa por ciento de los hospitales son propiedad 
del Estado, pero los pacientes pueden acudir al otro diez por ciento de hospitales particulares si así lo desean. Los costos en estos hospitales privados son muy bajos ya que el Gobierno otorga un subsidio de dos libras esterlinas semanalmente por cada paciente que sea atendido.

El Fondo de Seguridad Social otorga otras ayudas en caso de enfermedad, a familias que tengan un ingreso menor de $\$ 16.60$ a la semana.

Las Pensiones de Vejez devengan automáticamente a toda mujer que cumple los 60 años y a todo hombre que cumple los 65 años. Estas pensiones comenzaron con muy pequeños pagos, pero están avanzando semi-anualmente. E1 año 1939 llegaban a $\$ 39.84$ y en el año 1942 subieron a $\$ 66.40$ al año. La meta es el de pagar el equivalente de $\$ 258.96$ como pensión de vejez el año 1969. Este es el sistema más liberal de pensiones a la vejez que existe en el mundo hoy en día.

E1 Proyecto de Construcción de Viviendas detenido por la guerra, ha dado como resultado la construcción por el Gobierno de más de 10,000 (Población millón y medio de habitantes más o menos) casas cuyos costos oscilan entre $\$ 6,000$ y $\$ 8,500$ cada una, incluído el precio del terreno. Estas casas se arriendan entre $\$ 3.25$ a $\$ 5.70$ a la semana, de acuerdo con el tamaño y costo de la casa. Se calcula que arrendadas ininterrumpidamente se habrán amortizado y proporcionado al Estado una pequeña utilidad al término de 60 años.

A aquellos que desean construir sus propias casas, el Estado les presta hasta el $90 \%$ del costo del terreno y fábrica. con un interés de cuatro y un octavo por ciento al año y pagos escalonados, de tal manera que todo el préstamo puede ser saldado en un plazo de 20 ó 36 años a elección del prestatario.

Se han utilizado subsidios para mantener bajo el costo de vida, de tal manera que durante toda la guerra éste no ha subido sino un $13.4 \%$.

Los Servicios Públicos sujetos a control de precios han sido: Electricidad, gas y pasajes de omnibuses y tranvías. Precios topes han sido fijados para el carbón y otros combustibles. Dichos precios topes se han hecho extensivos así mismo para los alimentos y vestuario.

Actualmente se estudian planes para beneficiar a los ex-combatientes. Los mismos pueden ser divididos en tres categorías: satisfacer necesidades inmediatas de los desmovilizados; ayuda por corto plazo a aquellos que la necesiten en forma temporal antes de restablecerse económicamente y planes para asistencia prolongada para los casos en que los ex-combatientes no puedan ganarse la vida por sí mismos.

Un Consejo de Rehabilitación designado por ley del Congreso en el año 1941, ha elaborado proyectos para trabajos de irrigación y control de inundaciones, nuevas carreteras, desecamiento de pantanos y mejora de tierras, y desarrollos Hidro-eléctricos que pueden proporcionar en el momento trabajo para los primeros cuarenta mil hombres que sean desmovilizados.

E1 Tesoro Público ha establecido una cuenta especial denominada "Desarrollo Nacional" la cual financiará la reconstrucción industrial y que compensará a las personas y firmas que sufran la cancelación de sus contratos de guerra cuando cesen finalmente las hostilidades.

El Gobierno ha sido también autorizado para dar asistencia financiera directa para la conversión de las plantas de guerra y puede obligar a los patronos a mantener en planillas a aquellos hombres que han estado laborando en industrias de guerra y aun a emplear cierto número de ex-combatientes.

La Deuda Pública en Nueva Zelandia había llegado a mediados del año 1942 a la más alta cifra per capita de cualquier país en el mundo - casi $\$ 1,150$ por cada hombre, mujer y niño, 
Los impuestos son tan altos en este país que el pago de los mismos ha hecho casi desaparecer por completo la riqueza.

A su crédito tiene Nueva Zelandia el hecho de que tiene el comercio de exportación mayor del mundo por habitante; la cifra más baja de mortalidad en el mundo, incluso la infantil; el más alto porcentaje de casas propias y la mayor expectativa de vida en el mundo: más de 65 años para los hombres y más de 68 años para las mujeres.

La prueba suprema para el sistema de Nueva Zelandia va a venir después de la guerra en que desaparezca el estímulo económico artificial que ha traído y consistirá en determinar si las medidas de Seguridad Social existentes y en planeamiento pueden continuar sin llevar al país a la bancarrota. El peligro inmediato es que el Estado asuma obligaciones para con sus conciudadanos que no puedan ser soportadas más tiempo por los recursos económicos del país.

\section{Canadá}

El más rico Dominio del Commonwealth Británico ha elaborado ya su plan de Seguridad Social para el dia de la desmovilización.

Corre a cargo de la ejecución del plan la Oficina de Veteranos de Guerra, la cual examina las necesidades de cada ex-combatiente y ve la manera de satisfacerlas. Damos aćuí como ejemplo cuatro de los casos más comunes que pueden presentarse ante esta Oficina:

a) Agricultor.-El ex-combatiente se dirige a la sucursal más próxima de la Dirección de la Ley de Tierras para ex-combatientes en demanda de un certificado de calificación. Obtenido éste se presenta para un examen oral ante un Comité Voluntario Regional. Ante él debe demostrar que ha tenido por lo menos dos años de experieńcia agrícola y que se encuentra en plena posesión de sus facultades mentales $\mathrm{y}_{\mathrm{i}}$ físicas.

Considerando el Comité que el postulante se ha encontrado varios años ausente de la tierra debido a la Guerra decide que siga un curso de repaso. Así el solicitante y su familia son colocados inmediatamente en la chacra de un ciudadano competente de la localidad. Un Inspector Gubernamental vela porque el agricultor instruya al ex-combatiente en todas las fases de la administración de una chacra asi como del trabajo manual correlativo. De ser necesario, el ex-combatiente y su familia reciben un subsidio del Gobierno que puede llegar a 111 máximo de 13 dólares por semana.

Terminado el curso. el ex-combatiente se dedica a buscar una chacra propia. Revisa la lista de propiedades del Gobierno (El Canadá está actualmente comprando los miles de chacras necesarias para llenar las necesidades del Plan, concentrándose primero en aquellas de propiedad de agricultores mayores de 65 años sin hijos), pero se decide por una chacra ofrecida en venta por un particular. La Agencia Gubernativa la examina y acuerda pagar por clla el máximo permitido por la Ley de Tierras para Ex-Combatientes o sea $\$ 4,800.00$.

Habiendo hecho el primer pago requerido de $\$ 480.00$ o sea $10 \%$, el excombatiente firma contrato para devolver $\$ 3,200.00$ (dos tercios del costo de la tierra y mejoras), en un plazo de 25 años, con intereses a $3 \% / 2 \%$, sumando esto más o menos $\$ 12$ al mes.

Busca luego ganado y maquinaria y después de ser revisados éstos por la Agencia se le permite el crédito máximo de $\$ 1,200.00$.

Una viez instalado, el ex-combatiente se aconseja con el Representante del Servicio de Administración Agrícola para Ex-Combatientes. Juntos ana- 
lizan los distintos tipos de tierra en la chacra y deciden las semillas a comprar y las fechas en que deben ser plantadas. La estación siguiente los funcionarios del Gobierno lo mantendrán informado de las condiciones en los Mercados locales y distritales.

La ayuda financiera es continuada hasta que se cosechan los frutos. E1 ex-combatiente está calificado para recibir subsidios tantas semanas hasta un año como tiempo ha pasado en filas.

Transcurridos einco años, la Administración de la Ley de Tierras revisará minuciosamente la situación del ex-combatiente. Si encuentra que éste no se encuentra bien adaptado, se le relevará de sus obligaciones contractuales antes de que se arruine o fracase. Si permanece en la chacra y cumple con su contrato, terminados los diez primeros años se le dará título a los $\$ 1,200.00$ de ganado y maquinaria y al final de los 25 años los títulos de propiedad de la chacra. Esta es entonces suya para venderla o donarla a sus hijos.

El programa canadiense contempla el establecimiento en las labores agrícolas de 25 mil ex-combatientes, cantidad igual al colocado en el Agro después de la primera Guerra Mundial. Pero mientras en ese entonces los ex-combatientes canadienses encontraban las cargas económicas muy pesadas, esta vez el Gobierno ha contribuído con más o menos el $40 \%$ del costo total de la inversión. Además proporciona a los ex-combatientes consejos que muchas veces significan la diferencia entre dinero en el Banco y mayores deudas.

b) Empleado casado.-Este quiere tener una pequeña granja en el campo, a la vez que una ocupación en la ciudad, como fuente principal de ingresos.

El Oficial de Bienestar ayuda a este ex-combatiente a encontrar empleo como tenedor de libros. Ya con un ingreso asegurado, recibe ayuda gubernamental para la compra de un terreno de tres acres en las afueras de la ciudad. Después de satisfacer las exigencias de la Administración de la Ley de Tierras, recibe $\$ 300$ para el terreno; $\$ 2,500$ para construir una casa; $\$ 200$ para cercar la propiedad y abrir un pozo y $\$ 400$ para equipo.

El pago inicial que debe hacer es de $\$ 300$ con un saldo de $\$ 2,000$ (otra vez $2 / 3$ partes del costo de la tierra y mejoras) distribuído sobre un período de 25 años. Sus pagos mensuales por la adquisición de este confortable hogar suburbano son $\$ 10$.

c) Obrero.-Mientras el ex-combatiente busca trabajo recibe un subsidio de desocupación de $\$ 9$ semanal. Al encontrar un empleo descubre que debe tener cierto adiestramiento especial para desempeñarlo. El Oficial de Bienestar para Ex-Combatientes envía al solicitante a una Escuela Técnica pagando su alimentación, pensión de enseñanza y otros gastos. Tiene derecho a estos beneficios tantas semanas como haya servido hasta un máximo de 52 .

d) Estudiante-Previo examen por el Departamento de Pensiones y Salubridad Pública él regresa a la Universidad costeándole el Gobierno todo menos los libros.

Si mantiene sus notas él recibirá beneficios titulados de Universidad, por un período igual a las semanas que haya estado en servicio y si destaca notablemente se le facilitará el subsidio hasta que culmine su carrera.

La piedra fundamental de las recomendaciones hechas por Leonard C. Marsh en su "Informe sobre Seguridad Social para el Canadá", (Febrero de 1943), lo constituyen los Subsidios Familiares. El Sr. Marsh fijó sus propuestas para un sistema canadiense en el principio de un mínimo de ingreso 
de mantenimiento para todos los miembros de la población y señaló un lugar especial para un programa separado de Subsidios para los niños, declarando que: "Las necesidades de la niñez deben considerarse como una obligación especial de la Nación, no sólo en los períodos de desocupación o de calamidades sino en todos los tiempos".

La Ley de Subsidios Familiares de $1^{\circ}$ de Agosto de 1944 dice en su preámbulo: El futuro del Canadá depende de sus niños. Son la riqueza del país. Niños felices y sanos criados en una atmósfera de seguridad toman su lugar como miembros activos y productivos de la Sociedad.

Sin embargo, en las actuales condiciones, la carga mayor en la crianza de los niños de la nación recae en menos de un quinto del total de la población trabajadora. El valor del niño para la Comunidad no guarda relación alguna con el trabajo del padre o sus ingresos. Cada niño en la familia significa mayores gastos sin provisión de fondos adicionales con los cuales ellos puedan ser afrontados.

Los subsidios familiares van a ayudar a los padres canadienses a afrontar esta carga financiera. Dinero para el niño afluirá directamente al hogar. centro de la vida del niño, donde es alimentado, vestido y cuidado. Irá al padre y a la madre que conocen las necesidades individuales de la familia mejor que nadie.

Conforme avanzan los años estos subsidios familiares pueden ayudar a reducir las enfermedades, epidemias, criminalidad, analfabetismo, ineficiencia y otros males sociales que tienen sus raices en la forma cómo se cría a la niñez. Desde que son otorgados a gente que gastará el dinero ello creará una continua demanda de bienes y artículos que resultarán en una Producción y Empleo aumentadios.

- Los Subsidios Familiares constituyen una manera sencilla, igual y efectiva de asegurar una mayor medida de bienestar para los ciudadanos canadienses del futuro. Los Subsidios Familiares constituyen un capítulo en la Seguridad Social.

La ley acotada dispone que el Gobierno Canadiense concederá Subsidios Familiares para todos los niños dependientes por bajo la edad de 16 años. Estos Subsidios han comenzado a pagarse a partir del $1^{\circ}$ de Julio del año en curso con cargo a los ingresos generales del Canadá y sin recurrir a prueba de medios. La cantidad del subsidio varía con la edad del niño y también con el número de hijos en cada familia.

Por cada uno de los cuatro primeros hijos en una familia el subsidio es de $\$ 5$ al mes desde el nacimiento hasta la edad de 6 años; $\$ 6$ de 6 a 9 años; $\$ 7$, de 10 a 12 años y $\$ 8$, de 13 a 15 años. Para familias con más de cuatro hijos, el stubsidio por el quinto hijo se reduce en $\$ 1$; para el sexto y séptimo en $\$ 2$ y por cada hijo después del séptimo en $\$ 3$.

Los subsidios son pagaderos a los padres o a cualquier otra persona autorizada y deben ser aplicados "exclusivamente hacia el mantenimiento, cuidado, adiestramiento, educación y mejoramiento del niño". Si se encuentra que los subsidios no están llenando estos fines, el Ministro de Salud Pública y Bienestar o cualquier otro funcionario autorizado podrán suprimir el subsidio o abonar el mismo a otra persona o entidad para ser usada en beneficio del niño.

La ley contiene disposiciones contra la duplicación de beneficios, excepto aquellos que son exigibles bajo la ley de pensiones y subsidios de dependiente para los hijos de los miembros del ejército, marina y aviación. Específicamente, la cantidad que se autoriza a deducir por dependientes en el pa- 
go de impuestos, permitida bajo la ley de Impuestos de Guerra, será fijada para evitar duplicidad de beneficios entre las dos leyes.

El costo total anual por los $3 \frac{1}{2} \%$ millones de niños que son elegibles para subsidios se estima en $\$ 253$ millones. Desde que esta cantidad incluye los $\$ 50$ millones concedidos a los contribuyentes por dependientes, el costo neto será de $\$ 200$ millones. El costo de operación se estima que no sea mayor de $2 \%$.

Un Comité especial de Seguridad Social fué designado por la Cámara de los Comunes Canadiense en Marzo de 1943 para considerar e informar sobre la legislación de Seguridad Social a fin de suplementar y unificar los programas ya operantes. Un sistema nacional de seguro contributorio contra la desocupación fué establecido en Agosto de 1940. El Dominio concede también subsidios y otras ayudas para ex-combatientes. Un Programa Provincial del Dominio otorga pensiones de vejez y de ceguera y funcionan Sistemas Provinciales de Indemnizaciones para Obreros, Subsidios de Mater $\overline{n 1}$ dad y otros servicios de Asistencia Social.

Canadá es el tercer miembro del Commonwealth Británico en adoptar un programa nacional de Subsidios Familiares. Este está incluido en el Sistema de Nueva Zelandia, como ya hemos visto y Australia concede subsidios para cada hijo después del primero a todas las familias sin considerar sus ingresos. El sistema canadiense no pone limitaciones en relación al tamaño o a los ingresos de la familia.

Canadá busca así de dar libertad de oportunidad económica y un monto razonable de segurjdad social a toda su población.

\section{Inglaterra}

Un sistema de Subsidios por hijos es también uno de los tres principios básicos que subrayan las propuestas de Beveridge para la Seguridad Social en la Gran Bretaña, principio que también ha sido incluido en el Plan de Seguridad Social propuesto por el Gobierno Británico con fecha 25 de Setiembre del año de 1944.

El Partido Liberal ha dado a publicidad en las postrimerías del año pasado las propuestas de la Dama Rhys-Williams para coordinar la asignación de dependientes y otros subsidios sociales con el sistema general de los impuestos y finanzas nacionales. Tal como fué propuesto por March e incluído en la ley Canadiense, la Dama Rhys-Williams divorciaría el principio de subsidios para los dependientes de todos los trabajadores del principio de beneficios de seguros basados en aportes. Subsidios por dependientes de $£ 26$ al año para todo niño bajo los 15 años de edad o que concurrieran todavía a la escuela serían pagados de los impuestos generales; el Seguro Social sería restringido a Seguro de Desocupación y de Invalidez para los Trabajadores, a beneficios de Maternidad para las madres obreras y a parte del costo total de un servicio médico gratuito. Por esta propuesta el subsidio por hijos sería pagado a la madre aunque en casos especiales podría ser abonado al padre o tutor.

Por su especial importancia dejamos para próxima oportunidad el Informe de Sir William Beveridge sobre Seguros Sociales y Servicios Congéneres; el Plan del Gobierno Británico para Seguridad Social así como su Política de Empleo. Nuestra intención final es la de estudiar la política social de otros pueblos para luego situarnos en la realidad peruana con el in. tento de trazar rutas conforme a las cuales pueda elaborarse un amplio plan de Seguridad Social para nuestro país. 